\title{
The Effects of L2 Reading Skills on L1 Reading Skills through Transfer
}

\author{
Gonca Altmisdort ${ }^{1}$ \\ ${ }^{1}$ TMA, Ankara, Turkey \\ Correspondence: Gonca Altmisdort, TMA, Ankara, Turkey. E-mail: altmisdort_g@yahoo.com.tr
}

Received: June 10, 2016 Accepted: July 9, 2016 Online Published: July 10, 2016

doi: 10.5539/elt.v9n9p28 URL: http://dx.doi.org/10.5539/elt.v9n9p28

\begin{abstract}
This study investigated whether transfer from L2 to L1 in reading occurs, and if so, which reading sub-skills are transferred into L1 reading. The aim is to identify the role of second language reading skills in L1 reading skills by means of transfer. In addition, the positive effects of the second language transfer to the first language in the context of reading skills and sub-skills were analyzed. Fifty-three native Turkish-speaking adults English language learners were tested in this study. These participants were university students who had the same L1 Turkish proficiency backgrounds. While 26 students took L2 reading courses for four months, the other 27 students did not take any L2 reading courses. After four months of L2 reading courses, these two groups were given a standard L1 (Turkish) reading test. The Turkish reading test included vocabulary, comprehension, grammar and reading sub-skills questions. The results revealed that L1 reading skills were affected positively by the L2 reading skill transfer. The study reveals which L1 reading sub-skills are more developed by L2 reading skills transfer. For further studies, the correlations in L1 and L2 courses may open a way in language curriculum design. Both courses can be designed as an adjunct course formulated on the skill-based syllabus model, and reading skills can be transferred cross-linguistically. Thus, L2 reading proficiency will be transferred to L1 proficiency.
\end{abstract}

Keywords: interference, four skills, language acquisition, language learning, syllabus, proficiency

\section{Introduction}

First and second language acquisition has been a common interest in academic studies due to the increasing demand of second language education. First language (L1) and second language (L2) acquisition differ from each other. In second laguage acquisition, L2 learners bring all knowledge of their L1 to the L2, and they transfer their L1 language skills in to the L2. Most previous language transfer studies, tended to focus on L1 language influence on L2. The present study aims to contribute a different view of transfer from the L2 to the L1 by providing data from L2 learners with their first language, Turkish.

Transfer has a long history in language studies. The influence of the L1 has already been researched in many previous studies and the findings have pointed out the effects of L1 transfer (Gass \& Selinker, 2008; Garcia-Mayo, 2009; Snape, 2008; Goad \& White; 2009). The basic concept of transfer in language researches is that, when a second language is learned, some properties of the L1 are transferred into the L2 (Cook, 2000). In those studies, very few L2 researchers have attempted to address if L2 learners are able to reflect their L2 skills to L1.

In some research it is stated that transfer can go in two directions, from the L1 to the

L2 and from the L2 to the L1. Siu and Ho (2015), in their studies searched two-ways of language transfer. They examined the roles of syntactic skills by predicting reading comprehension in two different languages. The results of the study show that bilingual learners draw on the correspondence between L1 and L2 syntax to help their L2 learning process. However, in literature, the effects of the L2 on the L1 are generally considered only under the headings of "attrition" or "language loss". Although there are some studies on L2 transfer effects, almost all subsequent language studies went in the single direction from the L1 to the L2.

L2 transfer effects on L1 are a rarely studied subject. This study addresses that there is a positive transfer from the L2 to the L1 and the role of L2 reading skills transfer to the L1 by focusing on Turkish-speaking adult English learners. The reason for selecting these language groups was because each group had different L2 
language courses: One group of students had L2 reading courses for four mounths and the other group did not have any L2 reading courses. This study examined the role of L2 transfer and whether learners are able to develop their L1 reading skills by using their L2 reading skills.

Considering the four language skills, reading skills are easier to be noticed and evaluated. Although people have a great deal of information about the processes involved in reading in their native language, there is very limited research about $\mathrm{L} 2$ reading effects on the $\mathrm{L} 1$ as well. $\mathrm{L} 2$ learners transfer their $\mathrm{L} 1$ reading skills to $\mathrm{L} 2$ reading skills. Are L2 reading skills able to be transferred to L1 reading skills? This study is an attempt to find answer to this question through an investigation of L2 reading attitudes to the L1 by adult Turkish speakers. In the study, reading comprehension, and reading sub-skills are analyzed.

\subsection{Language Transfer}

There are many different definitions of transfer. Haugen (1956) referred to transfer as, 'the overlapping of two languages'. Odlin (1989) stated, "Transfer is the influence resulting from similarities and differences between the target language and any other language that has been previously acquired". In language learning or acquisition, the person finds themself in a language mode in that they are switching different skills. In this process, they interact with L1 sub-skills. The traces of these skills can be reflected to one language from another by means of transfer.

It is clear that the $\mathrm{L} 1$ affects the L2 in many ways. Linguistic transfer occurs when learners start to learn another language. They begin to use linguistic resources from their L1 ( Leafstedt \& Gerber, 2005). By cross-linguistic transfer, learners use L1 language to gain skills in the L2. These skills are generally written and oral language (Cardenas-Hagan, Carlson, \& Pollard-Durodola, 2007).

In recent research, many areas have been studied related to L1 transfer. Vazques (2014) compared the lexical transfer production of two groups of students and determined whether language proficiency was a key factor. The results show that there was no significant difference in language proficiency between both groups. Albirini and Benmamoun (2014), researched the impact of language transfer in majority-minority language contexts in both second-and heritage-language acquisition. The relationship between second-language transfer and incompleteness and attrition of heritage Arabic was analyzed. The results show that heritage speakers have various gaps in their knowledge of the examined areas, especially in forms and patterns. In another study, Moqimipour and Mohsen (2015) investigated writing errors which occured by the interference of the Persian language. The results show some first language interference errors can be grouped into some categories.

It can be seen that there are different types of language transfer. The L1 and the L2 were analyzed with the purpose of identifying structural similarities and differences, which either facilitated or impeded the acquisition of the L2 (Odlin, 1989). When there are similarities in languages, the learners recognized some features such as phonological forms and cognates, which were common for both languages. As a result, it can be easier to acquire the L2 that is closely related to the L1 (Connor, 1996). This situation can not be limited by the languages which have similarities in general. Language transfer is possible between languages which have less common features. While the transfer may occur among the languages from the L1 to the L2, it can be said that the transfer is likely from the $\mathrm{L} 2$ to the $\mathrm{L} 1$.

\subsection{Transfer of Skills}

Transfer in language involves many different types of interference. Among these types, there are many features of languages which influence each other such as grammar, definitions, vocabulary, pragmatics, syntax, functions, pronunciation. The four language learning skills (reading, writing, speaking and listening) also play a crucial role in language transfer. The transfer can produce different results for different language learners because of varied proficiency in the L1 and the L2.

Recent studies on reading skills transfer are generally interested in L1 transfer effects on L2 reading proficiency. Carlo and his colleagues (Carlo et al., 2014), investigated the role of the language of instruction in moderating the relationships between initial levels of English oral language proficiency. The instructed groups, advanced faster than the students without initial strong Spanish reading comprehension skills. Han (2012), examined the relationship between comprehension monitoring outcomes in L1 and foreign language reading among Chinese learners of English. The results suggest that there is a moderate positive relationship between L1 and foreign language comprehension monitoring.

Reading skills have an important role in language learning. Througout history, researchers have been interested in reading and reading comprehension. The nature of the mental skills involved in reading comprehension has been investigated in numerous studies. In 1968, Davis selected eight skills and constructed items to measure 
each of these skills. In 1972, Spearrit identified the sub-skills of reading comprehension by maximum likelihood factor analysis. He proved that four skills of recalling word meanings, drawing inferences from the content, recognizing a writer's purpose, attitude, tone, and mood, and following the structure of a passage are identifiable as basic separate reading skills. The current study focused on Spearrit's reading subskills and the items of the reading test were chosen according to these sub-skills.

This study is interested in whether L2 reading skills help develop L1 reading skills. It is also focused on which reading subskills can be improved more in L1 by the help of the L2 reading courses. In the study, the relationship between reading skills in the L2 and the L1 are evaluated.

\section{Method}

\subsection{Research Design}

The present study examines the relationship between English language learners' L2-L1 reading skills transfer and the effect of L2 reading courses on reading sub-skills in L1. Furthermore, it is questioned that whether there are any positive changes that might occur in L1 reading sub-skills. Answers to the following questions were examined:

1) Is there any effect of $\mathrm{L} 2$ on $\mathrm{L} 1$ ?

2) Do L2 reading skills influence L1 reading skills?

3) Do L2 learners develop their L1 reading skills by having L2 reading courses?

The study focuses on document analysis, literature review and experimental data that allow us to search language transfer both quantatively and qualitatively. Turkish and English have many differences in language structure. However, it was predicted that for reading skills level, learners would interact with each other. It was also predicted that the learners would improve their L1 reading skills via L2 reading skills based on L2 transfer effects.

\subsection{Research Sample}

The present study represents a sub-sample of a large longitudinal project focusing on language and reading development in Turkish-speaking English language learners. The student participants were 18-20- year-old sophomores in universities and were selected randomly. Two different Turkish-speaking English language learner groups who have upper/intermediate level of English were involved. Both groups of students attended the same departments at a university in Turkey. While the first group were 27 students (n:27) who did not have any L2 reading courses, the second group of students (n:26) had 4- month L2 reading courses. These students had the same backgrounds in L1 (Turkish) proficiency. The L1 courses before university years and L1 courses in universities had the same content and equal course hours. Hence, at the beginning of this study, it was accepted that these two groups had almost the same L1 proficiency.

\subsection{Research Instrument and Procedure}

\subsubsection{Month L2 Reading Courses}

One group of the participants took 4-mounth L2 English reading course, while the other group of participants didn't get any L2 reading courses. In this 4-month L1 reading course, the participants were given general reading proficiency lessons in which reading skills and subskills were taught. The course included reading sub-skills such as prediction, skimming, scanning, gist reading, and inferring. The students learned to find detailed information to guess the meaning of new vocabulary, and to locate general and detailed information in the text.

\subsubsection{Research Setting, Instruments and Procedure}

Data for the study were collected at the end of the spring semester after one group of students completed their L2 reading courses. After the 4-month L2 reading courses, both groups were given a standard L1 reading test. A pilot test was conducted with a group of six native Turkish speakers before the implementation of tests to the students. The standard Turkish test, which was administered to all participants, included different types of reading skills questions in their native tongue (Turkish). The test was given to the students, so that it could be determined whether they had the same or different proficiency in their native language reading level. The test took approximately 40 minutes to complete. In the test, there were 25 questions including five parts- vocabulary $(\mathrm{V})$, drawing inferences from the content $(\mathrm{C})$, recognizing writer's purpose $(\mathrm{R})$, following the structure of a passage (P) and grammar (G). The participants were asked multiple-choice questions and it was predicted they would choose the best answer with the help of their reading skills. The participants completed their tests in a single session. 


\subsection{Data Analysis}

In order to answer three research questions, a parametric data analysis was conducted for each language group. An independent samples t-test, and Levene's test were used to compare the means of two the independent groups. The group statistics are given in Table 1 . In the tables, the students who did not have reading courses are shown as "A"; and the students who had reading courses are shown as "B".

Table 1. Group statistics

\begin{tabular}{llllll}
\hline & Group & $\mathrm{N}$ & Mean & Std.Deviation & Std.Error Mean \\
\hline Scores & $\mathrm{A}^{*}$ & 27 & 58,222 & 13,188 & 2,538 \\
& $\mathrm{~B}^{* *}$ & 26 & 66,769 & 13,231 & 2,594 \\
\hline
\end{tabular}

*The students who did not take reading courses.

** The students who took reading courses.

In Table 1, the mean values of equality observation are tested between two groups. The mean of group A is 58,222 , and the mean of group B is 66,769 .

The results of the independent samples test are shown in Table 2.

Table 2. Independent samples test

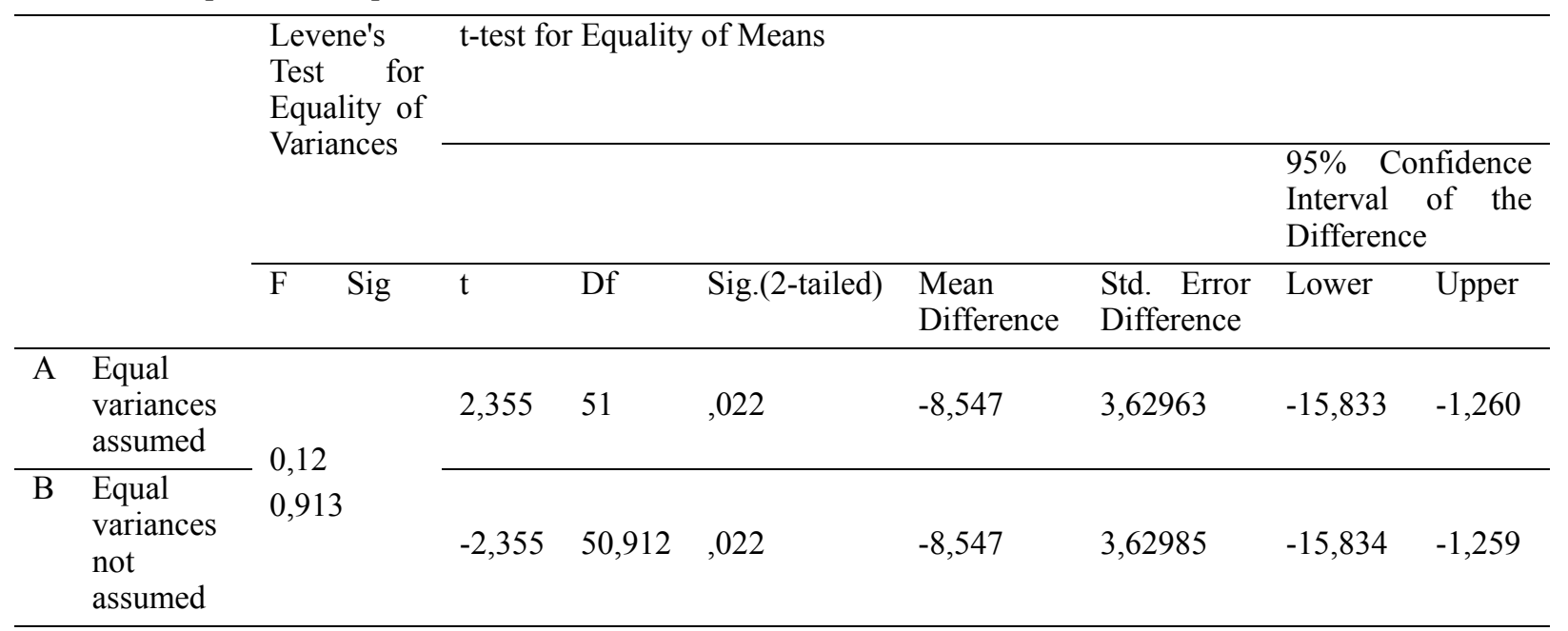

Levene's test was used to assess variance homogeneity. The results of the test show that there is homogeneity of variables. Since Levene's significance is $0,913>0,05$, we can accept the null hypothesis. Since $0,022<0,05$, H0 is rejected. There is a difference between two means. The results in Table 2 indicate that the students who took the $\mathrm{L} 2$ reading courses developed more in L1 reading than the students who did not have L2 reading courses.

Table 3. Dependent variables

\begin{tabular}{lllll}
\hline & & & \multicolumn{2}{l}{$95 \%$ Confidence Interval } \\
\hline Parts of the Test & Mean & Std. Error & Lower Bound & Upper Bound \\
\hline V (vocabulary) & 58,917 & 7,588 & 43,581 & 74,254 \\
C (drawing inferences from the content) & 69,644 & 7,588 & 54,307 & 84,981 \\
R (recognizing writer's purpose) & 55,142 & 7,588 & 39,806 & 70,479 \\
P (following the structure of a passage) & 75,043 & 7,588 & 59,706 & 90,379 \\
G (grammar) & 54,103 & 7,588 & 38,766 & 69,439 \\
\hline
\end{tabular}


Dependent variables for both groups are shown in Table 3. In the table, the means of the parts are given. Group effect is not measured. Both groups are evaluated as part of the test with a grade point average of one group, the standard errors and confidence intervals are shown in this table. The scores in the vocabulary section of the test (V) are in 95\% confidence interval and are located between 43.581 and 74,254. The scores in the drawing inferences from the content part (C) are in 95\% confidence interval and are located between 54,307 and 84,981. The scores in the recognizing writer's purpose part $(\mathrm{R})$ are in $95 \%$ confidence interval and are located between 39,806 and 70,479 . The scores in the following the structure of a passage part $(\mathrm{P})$ are in $95 \%$ confidence interval and are located between 59,706 and 90,379. The scores in the grammar part (G) are in 95\% confidence interval and are located between 38,766 and 69,439.

In Table 4, dependent variables are given for groups A and B separately.

Table 4. Dependent Variables: Scores

\begin{tabular}{lllll}
\hline & & & \multicolumn{2}{c}{$95 \%$ Confidence Interval } \\
\hline GROUPS & Mean & Std. Error & Lower Bound & Upper Bound \\
\hline A & 58,370 & 4,799 & 48,671 & 68,070 \\
B & 66,769 & 4,799 & 57,069 & 76,469 \\
\hline
\end{tabular}

According to Table 4, the means of group A (the students who do not attend reading course) are in $95 \%$ confidence interval and are located between 48,671 and 68,070. The means of group B (the students who attend reading course) are in $95 \%$ confidence interval and are located between 57,069 and 76,469.

\section{Results}

In this section the results of the data are presented. Firstly, the results of group A in their L1 test is discussed, then the results of group B in their L1 is discussed. Table 5 provides Dependent variables of Group A and Group B scores, group means and standard deviations; and Graph 1 shows the comparison of L1 reading test scores between Group A and B.

Table 5. Dependent variables: Scores

\begin{tabular}{llllll}
\hline & & & \multicolumn{2}{l}{$95 \%$ Confidence Interval } \\
\hline GROUPS & PARTS OF THE TEST & Mean & Std. Error & Lower Bound & Upper Bound \\
\hline A & V & 56,296 & 10,732 & 34,607 & 77,986 \\
& C & 58,519 & 10,732 & 36,829 & 80,208 \\
& R & 52,593 & 10,732 & 30,903 & 74,282 \\
& P & 77,778 & 10,732 & 56,088 & 99,467 \\
& G & 46,667 & 10,732 & 24,977 & 68,356 \\
& V & 61,538 & 10,732 & 39,849 & 83,228 \\
& C & 80,769 & 10,732 & 59,080 & 102,459 \\
& R & 57,692 & 10,732 & 36,003 & 79,382 \\
& P & 72,308 & 10,732 & 50,618 & 93,997 \\
& G & 61,538 & 10,732 & 39,849 & 83,228 \\
\hline
\end{tabular}

In Table 5, both groups are evaluated seperately as part of the test with a grade point average of one group, the standard errors and confidence intervals are shown. For group A, the scores in the vocabulary section of the test (V) are in 95\% confidence interval and are located between 34,607 and 77,986. The scores in the drawing inferences from the content part (C) are in 95\% confidence interval and are located between 36,829 and 80,208. The scores in the recognizing writer's purpose part $(\mathrm{R})$ are in $95 \%$ confidence interval and are located between 30,903 and 74,282 . The scores in the following the structure of a passage part $(\mathrm{P})$ are in $95 \%$ confidence interval and are located between 56,088 and 99,467. The scores in the grammar part (G) are in 95\% confidence interval 
and are located between 24,977 and 68,356.
V: $\mathrm{P}(34,607<\mu<77,986=0,95)$
C: $\mathrm{P}(36,829<\mu<80,208=0,95)$
$\mathrm{R}: \mathrm{P}(30,903<\mu<74,282=0,95)$
P: $\mathrm{P}(56,088<\mu<99,467=0,95)$
G: $\mathrm{P}(24,977<\mu<68,356=0,95)$

The possibility of $\mu$ in the range which is mentioned above is $95 \%$.

For group B, the scores in the vocabulary section of the test $(\mathrm{V})$ are in $95 \%$ confidence interval and are located between 39,849 and 83,228 . The scores in the drawing inferences from the content part (C) are in $95 \%$ confidence interval and are located between 59,080 and 102,459. The scores in the recognizing writer's purpose part (R) are in 95\% confidence interval and are located between 36,003 and 79,382. The scores in the following the structure of a passage part (P) are in 95\% confidence interval and are located between 50,618 and 93,997. The scores in the grammar part (G) are in 95\% confidence interval and are located between 39,849 and 83,228.
$\mathrm{V}: \mathrm{P}(39,849<\mu<83,228=0,95)$
C: $\mathrm{P}(59,080<\mu<102,459=0,95)$
R: $\mathrm{P}(36,003<\mu<79,382=0,95)$
$\mathrm{P}: \mathrm{P}(50,618<\mu<93,997=0,95)$
G: $\mathrm{P}(39,849<\mu<83,228=0,95)$

The possibility of $\mu$ the range which is mentioned above is $\% 95$. There is a meaningful difference in the rate of proficiency between the two group. The overall level of reading sub-skills for group B seems to be higher than that of Group A. The students in Group B have higher scores in four parts in L1 reading exam- vocabulary (V), drawing inferences from the content $(\mathrm{C})$, recognizing writer's purpose $(\mathrm{R})$, and grammar $(\mathrm{G})$. Group A is only successful in one part of the test- Part P (following the structure of a passage part ). This finding contrasts with our prediction, but when we compare the scores of this part for two groups it is seen that the scores are close to each other.

The main aim of this study was to analyze some basic skills of reading and to understand the effects of transfer. These data reflect some important details about the reading skill transfer from the L2 to the L1. The results of the study show that L2 reading courses change the L1 reading scores. Findings from this study suggest that Turkish-speaking students who take L2 (English) reading courses tend to show higher levels of reading skills transfer to L1 compared to the ones who did not take any L2 reading courses. According to the results, there is a relationship of L2 reading proficiency to L1 reading proficiency. Shortly, the present study shows that the reading skill in $\mathrm{L} 2$ can be transferred to $\mathrm{L} 1$ reading, and it affects the development of $\mathrm{L} 1$ reading skills.

\section{Discussion}

This study revealed some interesting findings regarding language transfer. The findings in relation to the research questions are as follows:

1) There are effects of L2 on L1.

2) L2 reading skills influence $\mathrm{L} 1$ reading skills.

3) L2 learners develop their L1 reading skills by having L2 reading courses.

In the present study, a number of errors occured in L1 reading tests by L2 learners who did not attend any L2 courses. The problem was related to the learners' lack of L2 reading skills and absence of L2 reading instruction, which focuses on reading sub-skills. Results from our analyses prove the L2 reading transfer to the L1 reading skills. In the study, the discussion focused on the possibility of positive L2 transfer. L2 reading may have quite differences with L1, however some basic, common features of that language can be transferred by reading skills.

\section{Conclusion}

This study contributes to previous research on language transfer, especially on L2 effects to L1 in reading skills. Although the limitation of the study is small, it can be a pioneer for further research. In this sense, the findings in the study have an important place for research regarding language reading proficiency and transfer.

The results of this study provides some new insights into how L2 learners transfer their L2 skills into L1. It was found that L2 reading skills and sub-skills effect L1 reading skills and sub-skills positively. For further studies, 
the correlations in L1 and L2 courses may open a way in language curriculum design. Both courses can be in the style of an adjunct course; and reading skills can be transferred cross-linguistically. These findings have important clues for instructors and program designers as they consider the type of program designing models that may be effective for students with varying L2 and L1 language abilities.

\section{Recommendations}

This study submits following suggestions to design adjunct and cross-linguistic L1 and L2 reading courses which are based on the skill-based syllabus model (White, 1988).

1) Two-language reading courses can be planned in $L 1$ and $L 2$.

2) The objectives of these reading courses should be planned from basic to advanced level.

3) The objectives of L1 reading courses should be integrated with L2 objectives.

4) The students should practice the theories and implementations of L2 reading skills in L1 reading courses.

5) The objectives of $L 1$ reading courses should be transferred to $L 2$ reading courses.

6) The contents of $L 1$ and $L 2$ reading programs should be integrated.

Thus, as the development in L2 reading courses is provided, this proficiency will be transfered to L1 proficiency. At the same time, when students reach the objectives of L1 reading courses, this time these skills will be transferred to L2 reading proficiency. These two-syllabus designs, which have detailed and well-planned objectives, will create an integrated, procedural and cylical model for developing L1and L2 reading skills simultaneously.

\section{References}

Albirini, A., \& Benmamoun, E. (2014). Aspects of second language transfer in the oral production of Egyptian and Palestian heritage speakers. International Journal of Bilingualism, 18(3), 244-273. http://dx.doi.org/10.1177/1367006912441729

Cardenas-Hagan, E., Carlson, C. D., \& Pollard-Durodola, S. D. (2007). The crosslinguistic transfer of early literacy skills: The role of initial L1 and L2 skills and language of instruction. Language, Speech, and Hearing Services in Schools, 38(3), 249-259. http://dx.doi.org/10.1044/0161-1461(2007/026)

Carlo, M. S., Barr, C. D., August, D., Calderon, M., \& Artzi, L. (2014). Language of instruction as a moderator for transfer of reading comprehension skills among Spanish-speaking English language learners. Bilingual Journal, 37(3), 287-310. http://dx.doi.org/10.1080/15235882.2014.963739

Cook, V. (2000). Talk to Budapest Pragmatic Symposium.

Connor, U. (1996). Contrastive Rhetoric: Cross-cultural aspects of second-language writing. Cambridge: Cambridge University Press. http://dx.doi.org/10.1017/CBO9781139524599

Davis, F. B. (1968). Research in comprehension in reading. Reading Research Quarterly, 3, 499-545. http://dx.doi.org/10.2307/747153

Gass \& Selinker, L. (2008). Second Language Acquisition: An introductory course (3rd ed.). New York, NY: Routledge.

Garcia-Mayo, M. P. (2009). Article choice in L2 English by Spanish speakers: Evidence for full transfer. In M. P. Garcia-Mayo, \& R. Hawkins (Eds.), Second language acquisistion of articles: Empirical findings and theoretical implications (pp. 13-35). Amsterdam: John Benjamins. http://dx.doi.org/10.1075/lald.49.05pil

Goad, H., \& White, L. (2009). Prosodic transfer and the representation of determiners in Turkish-English Interlanguage. In N. Snape, Y-Leung, \& M. Sharwood Smith (Eds.), In Representational deficits in SLA: Studies in honor of Roger Hawkins (pp. 1-26). Amsterdam: John Benjamins. http://dx.doi.org/10.1075/lald.47.04goa

Han, F. (2012). Transfer or threshold: The relationship between L1 and FL comprehension monitoring, Australian Association for Research in Education, paper presented at the Joint Australian Association for Research in Education and Asia-Pacific Educational Research Association Conference. World Education Research Association.

Haugen, E. (1956). Bilingualism in the Americas: A bibliography and research guide. Tuscaloosa: University of Alabama Press.

Leafstedt, J. M., \& Gerber, M. M. (2005). Crossover of phonological processing skills: A study of 
Spanish-speaking students in two instructional settings. Remedial and Special Education, 26, 226-235. http://dx.doi.org/10.1177/07419325050260040501

Moqimipour, K., \& Shahrokhi, M. (2015). The impact of text genre on Iranian intermediate EFL students' writing errors: An error analysis perspective, International Education Studies, 8(3), 122-137. http://dx.doi.org/10.5539/ies.v8n3p122

Odlin, T. (1989). Language transfer: Cross-linguistic influence in language learning. Cambridge: Cambridge University Press. http://dx.doi.org/10.1017/CBO9781139524537

Spearrit, D. (1972). Identification of Sub-skills of Reading Comprehension by Maximum Likelihood Factor Analysis, Educational Testing Service, Princeton, New Jersey.

Snape, N. (2008). The Acquisition of the English Determiner Phrase by L2 Learners: Japanese and Spanish. Germany: VDM Verlag.

Siu, T. C., \& Ho, S. C. (2015). Cross-Language transfer of syntactic skills and reading comprehension among young Cantonese-English bilingual students, Reading Research Quarterly, 50(3), 313-336. http://dx.doi.org/10.1002/rrq.101

White, R. V. (1988). The ELT Curriculum: Design, innovation and management, Basil Blackwell Ltd. Oxford, New York.

Vazquez, B. M. (2014). Lexical transfer in the written production of CLIL group and a non-CLIL group. International Journal of English studies IJES, 14(2), 57-76.

\section{Copyrights}

Copyright for this article is retained by the author(s), with first publication rights granted to the journal.

This is an open-access article distributed under the terms and conditions of the Creative Commons Attribution license (http://creativecommons.org/licenses/by/4.0/). 